\title{
Vitamin D Status of Behcet's Patients. Analysis of Correlation with Activity and Severity of the Disease as well as with the Quality of Life of Patients
}

Melek Kechida1, Olfa Harzallah'1, Ilhem Hellara², Rim Klii ${ }^{1}$, Fadoua Naffeti ${ }^{2}$, Mohamed Fadhel Najjar ${ }^{2}$, Silvia Mahjoub1

\section{Abstract}

Background: Vitamin D deficiency may increase the risk of various autoimmune diseases. But few studies focused on its role in Behcet syndrome.

Objectives: The aims of our study were to assess the vitamin D status of Behcet patients and to analyze the correlation of this status with the activity and the severity of the disease as well as the quality of life of patients.

Patients and methods: The vitamin D status was assessed in 40 patients with Behcet syndrome (average age: 37.5 years, sex ratio: 1.85) in comparison with 40 healthy control subjects matched by age, sex and by season of assessment. A correlation study was realized between vit $D$ levels and duration of disease progression, its activity, its severity as well as the quality of life of patients.

Results: The average rate of vit D was $14.64 \mathrm{ng} / \mathrm{ml}$ (3-44.29 ng/ $\mathrm{ml}$ ). $94.6 \%$ of them had hypovitaminose D. Vit D deficiency has been attested in $35.1 \%$ and insufficiency in $59.5 \%$ of the cases. There was no significant difference between rates of vit $D$ in Behcet patients and those of healthy controls. There was also no significant association between vit $\mathrm{D}$ levels in Behcet patients and duration of disease progression, activity and severity as well as their quality of life.

Conclusion: We made the evidence of hypovitaminose $D$ in Behcet patients. Even if its role in the determination of Behcet syndrome is not obvious, this track remains to be explored.
1 Internal medicine department, Fattouma Bourguiba Hospital, Monastir, Tunisia.

2 Biochemistry department, Fattouma Bourguiba Hospital, Monastir, Tunisia.

\section{Contact information:}

Melek Kechida.

Address: Internal medicine department, Fattouma Bourguiba Hospital, Monastir, Tunisia.

Tel: +21697292219 .

झ kechida_mel_lek@hotmail.com
Keywords
Behcet Syndrome; Vitamin D Deficiency; Disease Activity; Disease Severity; Patients' Quality Of Life. 


\section{Introduction}

Vitamin D (vit D) is a fat soluble vitamin existing in two forms: D2 [ergocalciferol) or D3 (cholecalciferol) [1-3].

To be biologically active, vit D (D2 or D3) needs to be converted to 25 hydroxy-vitamin D $(25(\mathrm{OH})$ D), which is an indicator of vit D status, than to 1 , 25 dihydroxy- vitamin $\mathrm{D}(1,25(\mathrm{OH}) \mathrm{D})$, which is the main active form $[4,5]$.

In addition to its role in calcium and phosphorus metabolism, vit $D$ has also an immunomodulatory function. It is, indeed, widely accepted that this hormone plays an active role in the regulation of both innate and acquired immune systems $[6,7,8]$.

A growing body of evidence supports the hypothesis that vit $D$ is involved in the pathogenesis of many immune diseases such as type 1 diabetes, atherosclerosis, systemic lupus erythematosus (SLE) $[9,10]$ or rheumatoid arthritis (RA) etc.... [11]. Levels of vit $D$ have been inversely correlated with disease activity in those disorders due to its immunomodulatory effects.

Very few studies have focused on vit $D$ rates in patients with Behçet's syndrome (BS) $[12,13]$.

The aims of our study were to determine the vit D status of Behcet patients and analyze the correlation of this vitamin status with the activity and severity of the disease as well as the quality of life of patients

\section{Patients and methods}

This is a descriptive analytical case-control study performed from March to May 2015. It prospectively enrolled 80 subjects [mean age 35.7 years, sex ratio: 1.8) divided into 2 groups: 40 patients with BS (Behcet group) (BG) and 40 healthy control subjects (control group) (CG) matched by age and sex.

\section{Description of study's population}

The diagnostic criteria for Behcet's Disease proposed by the "International Study Group of Behçet's
Disease" were used for diagnosis. All the patients were older than 20 years. Exclusion criteria were: pregnancy/breastfeeding, immobilization during the last 6 months, renal insufficiency (creatinine clearance $<60 \mathrm{ml} / \mathrm{min}$ ), intestinal malabsorption, calcemia $>2.65 \mathrm{mmol} / \mathrm{l}$, corticosteroids, calcium or vit D supplementation, thiazide diuretics, lithium, bisphosphonates or drugs based on vitamin $A$.

Control group (CG) are 40 healthy subjects matched for age and sex, recruited from the medical and paramedical staff of the hospital.

\section{Description of the study}

The study consisted first in:

- Obtaining the main demographic and clinical characteristics of patients through medical records analysis and a prospective data collection.

- Evaluating the activity of the disease in two ways:

- The opinion of an Internist specialized on Behçet's disease. Based on his assessment, the patients were divided into 2 subgroups: active Behcet group ( $A B G$ ) and inactive Behcet group (IBG).

- Evaluation by the Tunisian version of the Behcet's Disease Current Activity Form (TuBDCAF ) [14, 15].

- Assessing of the disease severity by the index of severity (IS) [16]

- Assessing of the quality of life of patients by the Behcet's Disease Work quality of life scale BDQoL [17]

- Determining the status of vit D of BG in comparison with that of healthy controls matched by age and sex (CG). Samples of both patients and controls were carried out during the spring.

- Vit $D$ deficiency was defined by a rate $<10$ $\mathrm{ng} / \mathrm{ml}[2]$

- Vit D insufficiency is defined by a rate between 10 and $30 \mathrm{ng} / \mathrm{ml}$ [2]

- Hypovitaminosis D was defined by a rate < $30 \mathrm{ng} / \mathrm{ml}[2]$

- $25(\mathrm{OH}) \mathrm{D}$ was considered as normal when the level > $30 \mathrm{ng} / \mathrm{ml}$ 


\section{Analytical study}

A first comparison interested sociodemographic characteristics, clinical and laboratory findings between $B G$ and $C G$. A second one concerned the characteristics of $A B G$ and IBG.

A correlation study was carried out between vit $D$ levels in BG and disease duration, its activity, severity as well as the quality of life of patients.

Biological assays

All biological parameters were done by the automated Cobas 6000 TM [Roche Diagnostics].

$25(\mathrm{OH}) \mathrm{D}$ levels were made by electrochemiluminescence immunoassay method [19] based on the principle of competition involving the vit $D$ binding protein (VDBP). This technique allows the measurement of the total vit $\mathrm{D}(25(\mathrm{OH}) \mathrm{D} 3$ and $25(\mathrm{OH}) \mathrm{D} 2)$ with an analytical specificity $\geq 98 \%$ for $25(\mathrm{OH})$ D3 and $\geq 81 \%$ for $25(\mathrm{OH}) \mathrm{D} 2$ respectively.

\section{Statistical methods}

Statistical analysis were performed using SPSS (Statistical Package for the Social Sciences) software program in its 18th release

Comparison of means was performed by Student's t test. Chi 2 test was done to compare qualitative parameters.

Correlations between quantitative parameters were studied using Pearson's coefficient (r).

A $p$ value of less than 0.05 was accepted as statistically significant.

\section{Approval of the ethics committee}

This study was approved by the Ethics Committee of the hospital. All patients and healthy controls were included in the study after a free and informed consent.

\section{Results}

The mean age of the patients was $37.5( \pm 11.75)$ years with a sex ratio of 1.85. Baseline sociodemographic characteristics of BG and CG groups are compared in table 1.
Table 1. Baseline sociodemographic characteristics comparison between Behcet group (BG) and control group (CG)

\begin{tabular}{|l|c|c|c|}
\hline \multicolumn{1}{|c|}{ Parameters } & BG & CG & P \\
\hline Age (years) & 37.5 & 37 & Ns \\
\hline Sex ratio (M/F) & 1.85 & 1.85 & Ns \\
\hline BMI (kg/m2) & 24.7 & 26.85 & 0.016 \\
\hline Smoking (\% of smokers) & 35 & 21.5 & 0.01 \\
\hline Alcohol intake (number of persons) & 1 & 3 & Ns \\
\hline Veiled (number of women) & $8 / 13$ & $4 / 13$ & Ns \\
\hline
\end{tabular}

Figure 1: The main clinical manifestations of Behcet group.

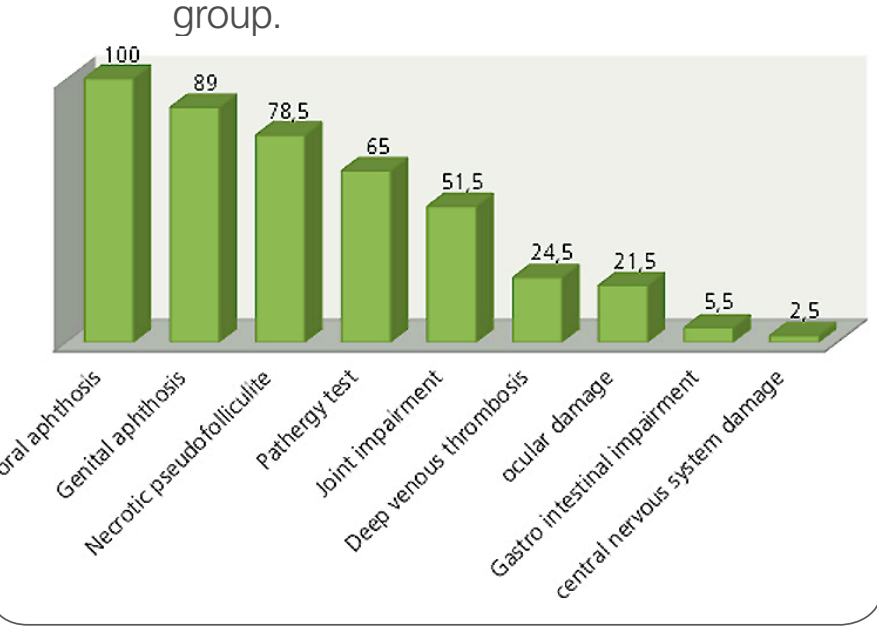

Mean disease duration in BG was $8.75( \pm 10)$ years. In $67.5 \%$ of them, BS evolved since the age of 10 and in $8 \%$ it evolved over 20 years. The main clinical manifestations are illustrated in Figure 1.

BS was considered active by the clinician in $40 \%$ of cases. The average BDCAF score was 4.86 (0-11). This score was greater than 6 in $38 \%$ of cases.

The average severity index was 4.7 (2-11). $81 \%$ of patients had a score below of 6 and only $2.7 \%$ of them above 10 .

The mean score for quality of life BDQoL was 7.78 (0-30). Two thirds of patients had a score between 0 and 10 and only $5.4 \%$ of them had a score between 20 and 30.

The mean vit D level in BG was $14.64 \mathrm{ng} / \mathrm{ml}(3$ to $44.29 \mathrm{ng} / \mathrm{ml}$ ). $94.6 \%$ of them had hypovitaminosis $\mathrm{D}$. There were $35.1 \%$ of vit $\mathrm{D}$ deficiency and 
Table 2. Comparative analysis of biological assays between Behcet and control groups.

\begin{tabular}{|l|c|c|c|}
\multicolumn{1}{|c|}{ Parameter } & $\begin{array}{c}\text { Patients } \\
\text { (BG) }\end{array}$ & $\begin{array}{c}\text { Controls } \\
\text { (CG) }\end{array}$ & P \\
\hline Calcemia (mmol/l) & 2.36 & 2.4 & 0.059 \\
\hline $\begin{array}{l}\text { \% of patients whith } \\
\text { hypocalcemia }\end{array}$ & 16.2 & $2.7 \%$ & 0.047 \\
\hline $\begin{array}{l}\text { Phosphorus }(\mathrm{mmol} / \mathrm{l}) \\
\text { Albuminemia }(\mathrm{g} / \mathrm{l})\end{array}$ & 1.01 & 1.03 & $\mathrm{Ns}$ \\
\hline Creatinemia $(\mu \mathrm{mol} / \mathrm{l})$ & 47 & 47.9 & $\mathrm{~ns}$ \\
\hline CRP $(\mathrm{mg} / \mathrm{l})$ & 84.8 & 89.6 & $\mathrm{~ns}$ \\
\hline $25(\mathrm{OH}) \mathrm{D}$ & 4.82 & 2.46 & $\mathrm{Ns}$ \\
\hline
\end{tabular}

Table 3. Comparison of the sociodemographic, clinical and biological characteristics between active Behcet group (ABG) and inactive Behcet group (IBG).

\begin{tabular}{|l|c|c|c|}
\multicolumn{1}{|c|}{ Parameter } & $\begin{array}{c}\text { ABG } \\
(\mathbf{n = 1 8})\end{array}$ & $\begin{array}{c}\text { IBG } \\
(\mathbf{n = 2 2 )}\end{array}$ & P \\
\hline Age (ans) & 35.4 & 38.95 & Ns \\
\hline Sex ratio (M/F) & $10 / 8$ & $14 / 8$ & Ns \\
\hline BMI (kg/m2) & 25.14 & 24.41 & Ns \\
\hline Smoking (PA) & 8.4 & 6.95 & Ns \\
\hline Calcemia (mmol/l) & 2.37 & 2.33 & Ns \\
\hline Hypocalcemia (\%) & 13.3 & 18.2 & Ns \\
\hline Phosphoremia (mmol/l) & 1.04 & 1 & Ns \\
\hline CRP (mg/l) & 6.01 & 4.01 & Ns \\
\hline BDCAF & 7.33 & 3.18 & $<0.00001$ \\
\hline BDQol & 7.53 & 7.95 & Ns \\
\hline Severity index & 5.06 & 4.45 & Ns \\
\hline
\end{tabular}

Figure 2: Comparison of vit $\mathrm{D}$ levels $(\mathrm{ng} / \mathrm{ml})$ between $A B G$ and IBG.

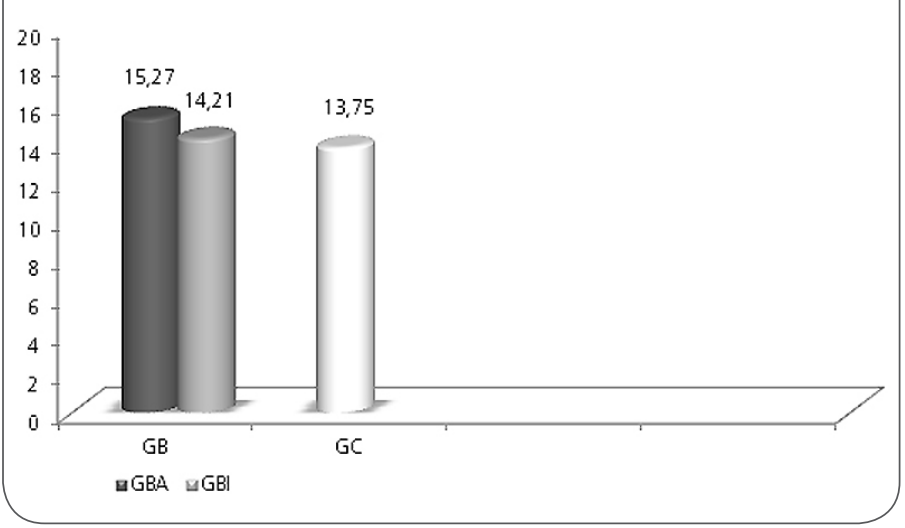

$59.5 \%$ of insufficiency. The comparative analysis of biological assays between BG and CG are shown in Table 2.

Vit $D$ levels were not significantly different in the 2 groups. They were rather decreased in controls.

Table 3 summarizes the results of the comparison of the sociodemographic, clinical and biological characteristics between $A B G$ and IBG.

Comparison of vit $D$ levels between $A B G$ and IBG is shown in Figure 2.

Correlation analysis did not find significant association between vit $D$ levels in BG and disease duration, activity, severity and the quality of life.

\section{Discussion}

There is growing scientific evidence that vitamin D is not only a vitamin but also a steroid hormone which plays an immunomodulatory role in many auto immune diseases [7, 18].

Vit $D$ modulates the expression of TLRs on the surface of blood monocytes in vitro, alters the ability of dendritic cells to present antigens to T cells by inhibiting their maturation, reduces the expression of MHC class II and appears to shift the Th1/ Th2 balance towards Th2 differentiation [7, 12, 19, 20].

The rational for the involvement of vit $D$ in the pathogenesis of BS seems clear. The BS is characterized by activation of neutrophil functions after activation and proliferation of Th1 lymphocytes, $T$ $\mathrm{V}^{+} \delta^{+}$and NK cells in response to antigenic hyperstimulation which is the consequence of an increase in the expression of MHC class II on the cell surface and activation of dendritic cells, dedicated to antigen presenting cells $[21,22,23]$.

Very few studies were interested in the status of vit $D$ in $B S$ patients and there were many conflicting results $[12,13]$

The assessment of disease activity in our study was achieved both by the impression of the clinician and by the BDCAF score [1, 15]. We used this 
score because it is a validated one, simple to use and reproducible.

The average BDCAF score in our patients was 4.86. No previous studies among those who assessed the vit D status in Behcet patients had used a clinical score to assess disease activity. One limitation of this activity score is the lack of a validated threshold defining disease flare. According to the clinician, the disease was active in $40 \%$ of cases in our study.

Do et al defined active BS by the presence of at least one clinical sign [12]. $56 \%$ of their patients were in flare-up during the evaluation. In the study of Karatay which included 32 patients with BS, only 3 had active disease [13]. Karatay et al also measured ESR and CRP on his patients.

The average CRP of our patients was $4.8 \mathrm{mg} / \mathrm{l}$. $16.2 \%$ of them had high CRP. We know that there is, for the moment, no laboratory marker correlated with disease activity and has even been shown that ESR, CRP and hemoglobin levels are not correlated with Behcet activity [24].

Often confused with the disease activity, severity is a different concept. As much as activity refers to clinical manifestations totally or partially reversible under treatment, as much as the severity refers to the sequelae and irreversible injuries arising from poorly controlled flares. There is no internationally validated severity score of $\mathrm{BS}$, for the moment. The only available index is the index of severity [16]. The mean severity index score in our patients was 4.7 ( \pm 1.86). The disease seems rather mild in most of them. Indeed, $81 \%$ had a severity index $<6$. The threshold defining a severe disease has also not been specified for this score.

Quality of life of our patients was assessed using a validated and specific score the BDQoL [20]. This Quality of life seems little altered. In fact two thirds of patients had a score $<5.5$, whereas only $10 \%$ of them had between 20 and 30 .

$25(\mathrm{OH}) \mathrm{D}$ was determined by electro chemiluminescence immunoassay method. It allows measuring the total $25(\mathrm{OH}) \mathrm{D}(25(\mathrm{OH}) \mathrm{D} 3$ and $25(\mathrm{OH}) \mathrm{D} 2)$. For years, vit $\mathrm{D}$ status was assessed by assaying 25 $(\mathrm{OH}) \mathrm{D} 3$, given that the latter is the major circulating form of vit D [5] and that $25(\mathrm{OH}) \mathrm{D} 2$, characterized by low affinity to DBP [carrier of vit D protein], has a rapid clearance [2]. Currently, several studies have shown that $25(\mathrm{OH})$ D2 is also important in the determination of the status vit D [2] and it is recommended by the Health Authority to measure $25(\mathrm{OH}) \mathrm{D}$ (D2 and D3) so avoiding undervaluing vit $D$ levels [25].

It is now established that $25(\mathrm{OH}) \mathrm{D}$ levels less than $10 \mathrm{ng} / \mathrm{ml}$ define a deficit and those between 10 and $30 \mathrm{ng} / \mathrm{ml}$ define a vit D insufficiency. These thresholds have been established according to the impact of vit D status on bone homeostasis but are still a source of controversy. In fact, vit D requirement for an optimal bone metabolism is $30 \mathrm{ng} / \mathrm{ml}$, but the required rate for the homeostasis of the immune system is still not established [2].

Do et al [12] found on his study that the frequency of patients with BS having vit D deficiency was almost double of ours [61\% vs 35\%]. Those with hypovitaminosis $\mathrm{D}$ were not specified. The threshold $(<10 \mathrm{ng} / \mathrm{ml}$ ) fixed by Do et al to define a vit $D$ deficiency was similar to ours as well as the average age of patients. The BMI of the patients was not specified. The higher frequency of patients with vit $D$ deficiency in the South Korean series is multifactorial: a higher frequency of females ( $S R=0.7$ vs. 1.8), blood samples taken during the winter, ours have been done in the spring, 37\% of patients on corticosteroid therapy while we excluded them from our study (table 4).

Karatay et al [13] did not specify the number or frequency of patients with hypovitaminosis, or vit D deficiency in their study, but they showed an average level of vit $D$ significantly reduced in patients compared with healthy controls.

This result was not found in our study or that of Do et al [12] (table 4). 
Table 4. Comparative study of the most principle epidemiological, clinical and biological results.

\begin{tabular}{|c|c|c|c|c|c|c|c|c|c|}
\hline & \multicolumn{3}{|c|}{ Do et al $(n=49)(9)$} & \multicolumn{3}{|c|}{ Karatay et al $(n=32)(5)$} & \multicolumn{3}{|c|}{ Our study ( $n=37$ ) } \\
\hline Country & \multicolumn{3}{|c|}{ South of Corea } & \multicolumn{3}{|c|}{ Turkey } & \multicolumn{3}{|c|}{ Tunisia } \\
\hline Mean age (years) & \multicolumn{3}{|c|}{$39.07(29-49)$} & \multicolumn{3}{|c|}{$29(18-50)$} & \multicolumn{3}{|c|}{$37.5(19-60)$} \\
\hline Sex ratio & \multicolumn{3}{|c|}{0.7} & \multicolumn{3}{|c|}{0.8} & \multicolumn{3}{|c|}{1.8} \\
\hline Saison (of assessment) & \multicolumn{3}{|c|}{ winter } & \multicolumn{3}{|c|}{ Not specified } & \multicolumn{3}{|c|}{ Spring } \\
\hline Mean disease duration (years) & \multicolumn{3}{|c|}{ 10. 6} & \multicolumn{3}{|c|}{2.75} & \multicolumn{3}{|c|}{8.75} \\
\hline $\mathrm{BMI}(\mathrm{kg} / \mathrm{m} 2)$ & \multicolumn{3}{|c|}{ Not specified } & \multicolumn{3}{|c|}{24.7} & \multicolumn{3}{|c|}{24.7} \\
\hline \% patients (steroids) & \multicolumn{3}{|c|}{37} & \multicolumn{3}{|c|}{16} & \multicolumn{3}{|c|}{0} \\
\hline$\%$ patients under colchicine & \multicolumn{3}{|c|}{98} & \multicolumn{3}{|c|}{84} & \multicolumn{3}{|c|}{100} \\
\hline$\%$ patients with flair & \multicolumn{3}{|c|}{56} & \multicolumn{3}{|c|}{ Not } & \multicolumn{3}{|c|}{40} \\
\hline vit D mean rate $(\mathrm{ng} / \mathrm{ml})$ & \multicolumn{3}{|c|}{11.66} & \multicolumn{3}{|c|}{13.76} & \multicolumn{3}{|c|}{14.64} \\
\hline \% hypovitaminose & \multicolumn{3}{|c|}{$\mathrm{np}$} & \multicolumn{3}{|c|}{$\mathrm{np}$} & \multicolumn{3}{|c|}{94.6} \\
\hline$\%$ vit D deficiency & & 61.1 & & & $\mathrm{np}$ & & & 35.1 & \\
\hline Patients vs controls & $\begin{array}{c}\text { Vit d } \\
\text { (patients) }\end{array}$ & $\begin{array}{c}\text { Vit D } \\
\text { (controls) }\end{array}$ & $P$ & $\begin{array}{c}\text { Vit d } \\
\text { (patients) }\end{array}$ & $\begin{array}{c}\text { Vit D } \\
\text { (controls) }\end{array}$ & $P$ & $\begin{array}{c}\text { Vit d } \\
\text { (patients) }\end{array}$ & $\begin{array}{c}\text { Vit D } \\
\text { (controls) }\end{array}$ & $P$ \\
\hline & 11.66 & 14.01 & ns & 13.76 & 18.97 & $<0.001$ & 14.64 & 13.75 & ns \\
\hline & & & & & & & & Ns: not sig & ifican \\
\hline
\end{tabular}

We were not able to notice any statistically significant difference in vit $D$ rates between patients and controls and unlike expected results, the average level of vit $\mathrm{D}$ was rather decreased in controls. Do et al [12] found the same thing in controls but was not significant after adjustment for age, gender and sampling season.

The fall in vit $D$ on the controls could also be explained by their exclusive recruitment from the medical and paramedical staff, who are not exposed to sunlight $[26,27]$.

The average rate of vit $D$ in $A B G$ did not significantly differ from that of IBG. There was also no significant correlation between levels of vit $D$ and the disease activity score.

There was also no significant association between the "severity index" assessing the disease severity and levels of vitamin D. Previous studies have not examined the relationship between patients' vit $D$ status and disease severity $[12,13]$.

As the severity index is not a validated score we cannot formally eliminate the association between vit $D$ deficiency and severity of the disease especially as the number of patients in our study remains low.

The exclusion of patients on corticosteroid therapy indirectly excludes very active and severe forms of the disease and thus makes any analysis of correlation with the activity as well as the severity of the disease difficult.

There was also no link between the status of patients in vit $D$ and duration of disease progression (DDP) or with the quality of life of patients, unlike Karatay study [13].

No previous studies have explored the possible link between vit $D$ status in patients with $B S$ and quality of life $[12,13]$.

Very few studies on this subject have been made and the multitude of factors involved in the metabolism and function of vit $D$ makes interpretation of their results difficult.

\section{Conclusion}

Although the role of vit D deficiency in the determination of the BS is not obvious, this track remains to be explored. The vit $D$ could be an adjunct 
therapy of the BS and this issue certainly deserves further studies with a larger number of patients, more active and more severe forms of the disease and a comparable sun exposure between patients and control subjects.

\section{References}

1. Holick MF. The photobiology of vitamin $D$ and its consequences for humans. Ann N Y Acad Sci 1985; 453: 1-13.

2. Binkley N, Ramamurthy R, Krueger D. Low Vitamin D Status: Definition, Prevalence, Consequences and Correction. Rheum Dis Clin N Am 2012; 38: 45-59.

3. Holick MF. Environmental factors that influence the cutaneous production of vitamin D. Am J Clin Nutr 1995; 61: 638S-45S.

4. DeLuca HF. The vitamin D story: a collaborative effort of basic science and clinical medicine. FASEB J 1988; 2: 224-36.

5. Christakos S, Ajibade DV, BAa, Dhawan P, Fechner AJ, Mady JL. Vitamin D: Metabolism. Rheum Dis Clin N Am 2012; 38 2012: 1-11.

6. Bikle DD. What is new in vitamin D: 2006-2007. Curr Opin Rheumatol 2007; 19: 383-8.

7. Martin Hewison. Vitamin D and the Immune System: New Perspectives on an Old Theme. Rheum Dis Clin N Am 2012; 38: 125-139.

8. Bouvard B, Annveiller C, Sallé A, Beauchet O, Chappard D, Audran $\mathrm{M}$ et al. Les effets extra-osseux de la vitamine $\mathrm{D}$ : faits, questions et controverses. Revue du rhumatisme. 2010; 775: A18-A25.

9. Gatenbya P, Lucasb R, Swaminathan A. Vitamin D deficiency and risk for rheumatic diseases: an update. Curr Opin Rheumatol 2013, 25: 184-91.

10. Kamen D, Aranow C. Vitamin D in systemic lupus erythematosus. Curr Opin Rheumatol 2008; 20: 532-7.

11. Liao KP, Alfredsson L, Karlson EW. Environmental influences on risk for rheumatoid arthritis. Curr Opin Rheumatol 2009; 21: 279-283..

12. Do J, Kwon SY, Park S, Lee ES. Effects of vitamin D on expression of Toll-like receptors of monocytes from patients with Behçet's disease. Rheumatology 2008; 47: 840-8.

13. Karatay S, Yildirim IK, Karakuzu, Kiziltunc A, Engin RI, Eren YB et al. Vitamin D status in patients with Behcet's Disease. Clinics 2011; 66[5]: 721-3.

14. Bhakta BB, Brennan P, James TE et al. Behçet's disease: evaluation of a new instrument to measure clinical activity. Rheumatology 1999; 38: 728-33.

15. Harzallah O, Meksi Y, Atig A, Hamzaoui A, Bchir, Rassas M et al. A Tunisian version of the Behçet's Disease Clinical Activity Form. 14th International Conference on Behçet's Disease. London 8th10th July 2010.

16. Yazici $H$, Tüzün $Y$, Pazarli $H$. Influence of age of onset and patient's sex on the prevalence and severity of manifestations of Behçet's syndrome. Ann Rheum Dis 1984; 43: 783-9.

17. Gilworth G, Chamberlain MA, Bhakta B, Haskard D, Silman A, Tennant A. Development of the BD-QoL: a quality of life measure specific to Behçet's disease. J Rheumatol 2004; 31: 931-7.
18. Szymanowicz A, Devaux C, Neyron MJ. Comparative study of the serum measurement of $25-\mathrm{OH}$ vitamin D3 on the Roche

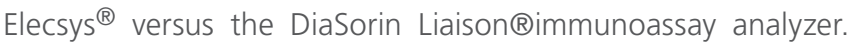
Immuno-analyse et biologie spécialisée 2009 ; 24: 160-5.

19. Briot K, Audran M, Cortet B, Fardellone P, Marcelli C, Orcel P et al. Vitamine D: effet osseux et extra-osseux ; recommandations de bon usage. Presse Med. 2009; 38: 43-54.

20. Diane L. Kamen VT. Vitamin D and molecular actions on the immune system: modulation of innate and autoimmunity. J Mol Med. 2010; 88(5): 441-50.

21. Peelen $E$, Muris AH, Thewissen M, Smolders JWCT, Hupperts R, Jan Damoiseaux. Effects of vitamin $D$ on the peripheral adaptive immune system: A review. Autoimmunity Reviews 2011 Oct; 10(12) 733-43.

22. Sakane T, Takeno M, Suzuki N, Inaba G. Behçet's disease.N Eng J Med 1999; 341: 1284-91.

23. Verity DH, Wallace GR, Vaughan RW. Behçet's disease: from Hippocrates to the third millenium. Br J Ophtalmol 2003; 87: 1175-83.

24. Verity DH, Wallace GR, Vaughan RW. Behçet's disease: from Hippocrates to the third millenium. Br J Ophtalmol 2003; 87: 1175-83.

\section{Comment on this article:}

\section{(f) $[$ in $8+\mathbf{S}$ P}

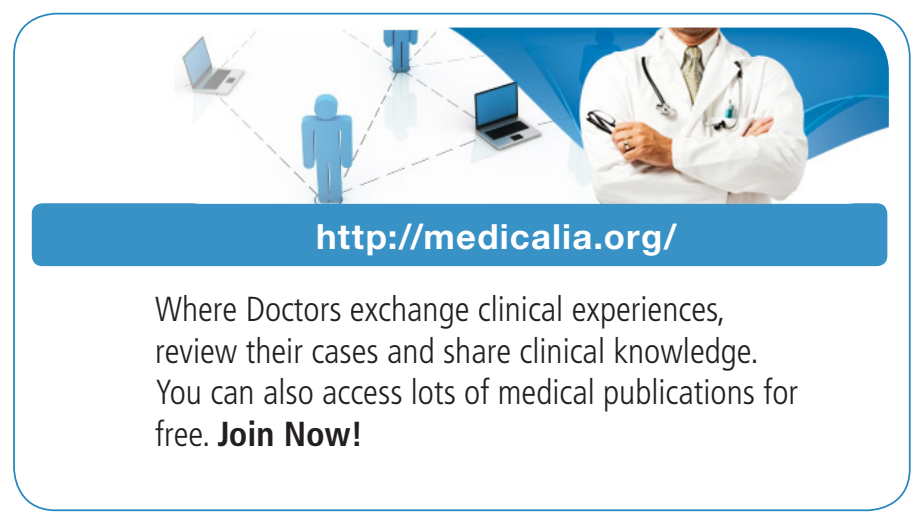

\section{Publish with iMedPub}

http://www.imed.pub

International Archives of Medicine is an open access journal publishing articles encompassing all aspects of medical science and clinical practice. IAM is considered a megajournal with independent sections on all areas of medicine. IAM is a really international journal with authors and board members from all around the world. The journal is widely indexed and classified Q1 in category Medicine. 